\title{
MEASURING IMMEDIATE RECOVERY FROM GENERAL ANAESTHESIA USING A SCORING SYSTEM
}

\author{
A.J. AsBury
}

\begin{abstract}
The study describes the design and testing of a scoring system to measure immediate recovery from anaesthesia. The scoring system which measures the patient's cognitive, motor, haemodynamic and respiratory recovery, was applied in 1,626 patients. The score was measured at five minute intervals and the results were plotted on recovery graphs for each patient.

The analysis shows that patients who had received automatic ventilation during their anaesthetic were likely to arrive in the recovery room with a score of 14 or 15 (the top score), while other patients were likely to arrive with lower scores and progressed in their recovery at 0.9 (SD 0.6) score units per minute.

Multivariate analysis confirms that the anaesthetist's decision to employ automatic or spontaneous ventilation is the most important single factor in determining the rate of increase of the recovery score.

It is suggested that this scoring system, which fits well with the clinical appreciation of the case, is a useful tool in the hands of the recovery nurse.
\end{abstract}

Key Words: Recovery, General Anaesthesia, Scoring System.

THE IMMEDIATE RECOVERY period is a dangerous part of the anaesthetic and, in one study, ${ }^{\prime}$ up to 62.1 per cent of deaths occurred in the early recovery period. ${ }^{2.3}$ If recovery management is inadequate, all the elegance of the surgery and anaesthesia will be wasted.

There are two main problems associated with recovery immediately after anaesthesia: delegation of care, and monitoring the patient. Usually the anaesthetist will delegate recovery care of the patient to a recovery nurse, while he starts the next case. The recovery nurse has to take over the patient who is in a rapidly changing state between surgical anaesthesia and full consciousness. The nurse may have little idea of the patient's individual response to drugs in relation to the anaesthetic (e.g. analgesics) unless specifically informed by the anaesthetist.

Monitoring of the patient in the immediate recovery period is frequently unsatisfactory, as the standard nursing observations of pulse, blood pressure and respiratory rate give little indication of the progress of recovery. This lack of a measurement of recovery progress makes it difficult for the nursing staff to communicate details

A.J. Asbury, M.B., Ch.B., F.F.A.R.C.S., Lecturer in Anaesthesia, Sheffield University, England.

Correspondence to: Dr. A.J. Asbury, University Dept. of Anaesthetics, The Medical School, 5, Beech Hill Road, Sheffield, S. 10 2RX England. of the patient's progress to the anaesthetist or to other nurses when the shift changes.

A further problem is that without a clear measurement system with normal ranges, the nurse is unable to identify a patient whose recovery progress is abnormal, and who should be detained in the recovery area.

One possible solution to this problem is to introduce some form of monitoring equipment to the recovery area, for example the Cerebral Function Monitor, a commercial device designed to monitor and display the integrated EEG during anaesthesia and recovery, and to apply it to all patients. The effect of this, however, could be to distract the attention of the nurses from the patient, to adjusting the equipment. It could be argued that such extensive monitoring was unnecessary in all cases, for example those lasting only five minutes.

A better solution to this problem would be to use the information already collected by the nurse in a better way, and to combine it simply so that a single number, a recovery progress score (RPS), would emerge. The RPS could be plotted against time by the attending nurse, instead of plotting pulse.

Several useful scoring systems have been devised from the simple score designed by Steward ${ }^{4}$ to more complex examples. ${ }^{5.6}$ One common disadvantage in these systems is the vagueness of

Can. Anaesth. Soc. J., vol. 28, no. 6, November 1981 
some elements, for example the consciousness scale. ${ }^{4.5}$ Another important problem is that the ability to maintain a clear airway, which is essential to life, is given no special weighting. ${ }^{4}$

Another scoring system, ${ }^{7}$ designed as part of a study on the effects of doxapram, gives much more attention to the airway and requires measurement of the score at two-minute intervals. This study is of particular interest as combining the scores of the fifty control patients and, plotting them against time, gives a function that is nearly linear with correlation coefficient of 0.89 . While not suggesting that recovery is a linear process (an exponential would be expected), it is suggested that a lincar approximation might give a helpful initial representation of the data.

The long term objective of this project is to improve the safety of recovery care by improving the detection of abnormal recoveries. This process requires several steps, the first of which is the quantification of a wide range of recovery patterns, as presented in this paper.

The next step is to compare different methods of monitoring recovery, for example by the Cerebral Function Monitor, to determine whether the recovery score can be improved by adjusting the emphasis on the different features, such as the airway.

The third step is to design a recovery monitoring chart for use by the nurses, which allows plotting of the score and incorporates 'action' boundaries. If the line of the graph crosses the action boundary, the patient's progress may be abnormal and should be called to the attention of the doctor.

A final step is to study the characteristic of patients falling outside the boundaries of normal recovery to see if the anaesthetic technique could be improved.

\section{Patients and Methods}

The new scoring system (Table I) has many features of existing systems. In the testing of neuromuscular function, the author considers that the most important muscular activity is adequate ventilation, and while not being in itself a test of the neuromuscular system, the observation gives useful information and focuses attention on this vital function. More precise tests of neuromuscular functioning ${ }^{8}$ are feasible once ventilation is secure.

Testing of conscious level is inevitably linked with neuromuscular function. The testing of the unrecovered patient follows patterns already
TABLE I

ThE NEW SCORING SYSTEM

No respiratory movement al all

Adequate breathing Tidal volume at least $300 \mathrm{ml}$. in adult)

Able to move all limbs to command

Able to lift head for 5 secs with closed mouth

No response to pain at all

Non-specific response to pain

Verbal response to spoken word

Colour test negative

Colour test positive

Tolerates airway or ETT

Will not tolerate airway or ETT

Systolic B.P. $\pm 30 \mathrm{~mm}$ pre-op level Systolic B.P. above $70 \mathrm{~mm} \mathrm{Hg}$, but less than

Pre-op value less $30 \mathrm{~mm} \mathrm{Hg}$

Systolic B.P. less than $70 \mathrm{~mm}$

Central cyanosis (tongue and in mouth)

Peripheral cyanosis/pallor/sweating

Pink/warm/well perfused

The total score is the sum derived from each section

used by many anaesthetists, but the main problem occurs when a patient seems to be speaking rationally and some further test of cerebral recovery is required.

In the "colour test" of visual perception, the subject is asked to name two colours pointed out by the nurse, from a card of 4 , each colour block being 4 " by 4 ". Failure in this test was scored 3 (Table I) as the patient has some verbal ability at this stage though not enough to satisfy the test. This was found to be more helpful than asking subjects to identify letters, which was tried in a pilot study.

The scoring for airway consciousness and safety has been simplified, as the author believes that it is better to combine assessment and treatment of the airway rather than have the nurse manipulate the airway to assess it, as suggested by some authors, ${ }^{9,10}$ The phenomenon of patients who will not tolerate an airway or tracheal tube during wakening is a clinical observation well known to anaesthetists, and this observation is heavily weighted in the score. Though it would have been possible to allocate separate scores for tolerance of the tracheal tube and pharyngeal airway, the author felt very strongly that the airway should be treated simply as safe or unsafe. A gradation of scores could encourage a gradation of attention. The skin colour assessment has been included, but without the reference to jaundice used in previous systems. ${ }^{5}$

One important consideration in the application 
of this system is that the constant attention may serve to regularly stimulate the patient, thereby altering the scores. This is unavoidable. There is also the problem of a spurious improvement in score by the patient learning the correct responses. The author suggests that if the patient can learn from the experience, then he has no need of a recovery score.

The study was done in a District General Hospital, which has 616 beds and a five-bedded recovery area serving three operating theatres. All recovery bays are equipped to administer oxygen, suction, and one bay has an automatic ventilator. Many of the patients leaving the recovery area must be transferred by ambulance to outlying wards, so the need for a clear indication of when to transfer patients was obvious to all staff. The weekly theatre sessions were general (12), ear, nose, and throat (5), gynaecology (6), urology (3) and dental (2) surgery, with one session for bronchoscopy (1). Table II shows an analysis of the types of cases classitied according to site of operation. The percentage of minor cases in each speciality were general 49 per cent, ear, nose and throat 46 per cent, gynaecology 60 per cent, urology 50 per cent and dental 43 per cent respectively. All patients went to the recovery room after operation.

A computer compatible record was designed to aid data collection and its effectiveness was tested in a pilot study of 76 cases. Data were lost mainly due to the fact that the record took too long to complete when the operation lasted only a few minutes. The record was redesigned to eliminate this potential source of bias.

The final method used in the study was for the anaesthetist to complete part of the study record giving details of the patient, the operation, and the anaesthetic. The record was then passed with the patient to the recovery room, where the details of recovery scores and times were inserted. The recovery nurses, who had been trained in the use of the score during the pilot study, were instructed to assess the recovery score on entry to the recovery area and at each five minute interval thereafter, until a score of 15 had been reached.

The completed records were collected and checked each week. If the records had information missing, such as age or type of operation, this was completed by reference to the patient's notes; but if any other data were missing, such as a recovery score, the record was discarded. In the duration of the study, 11 records were discarded leaving 1,626 correctly completed records.
TABLE II

Analysis of All Cases Subdivided by Detall of Operation, Anaesthetic, the Patient and the RECOVERY

\begin{tabular}{lc}
\hline \hline & Per \\
\hline Patient Analysis & Number \\
\hline
\end{tabular}

Patient Analysis

Number of Males

Number of Females

$583 \quad 35.9$

Number of minor operations

Number of major operations

Number of cases with SV

Number of cases with IPPV

$1043 \quad 64.1$

Number of cases with halothane

$\begin{array}{lrr}\text { Number of cases with halothane } & 1203 & 74.0 \\ \text { Number of cases with trichloroethylene } & 7 & 0.4\end{array}$

$1008 \quad 62.00$

$618 \quad 38.00$

$1110 \quad 68.3$

$\begin{array}{ll}516 & 31.7\end{array}$

$\begin{array}{lll} & & 0.4\end{array}$

$\begin{array}{lll}\text { Narcotics analgesics not used } & 720 & 44.3\end{array}$

Narcotics analgesic as premedication $\quad 456 \quad 28.0$

$\begin{array}{lll}\text { Narcotic analgesics during operation } & 296 & 18.2\end{array}$

Narcotic analgesics used as pre-med. and during operation

$154 \quad 9.5$

Anaesthetist's Expectation of Recovery

Normal recovery expected

Abnormal recovery expected

Operations classified by site/type

Abdominal wall (no thernia)

Arm/leg

Bronchoscopy, laryngoscopy, oesophagoscopy

Chest wall

Cystoscopy, sigmoidoscopy

1591

Ear

Eye

Head, neck (not throat)

Hernia orifices

Intracranial

Intra thoracic

Kidney retroperitoneal

Lower intra-abdominal/laparoscopy

Mouth, dental and faccomaxillary

Nose/throat

Obstetric

Obstetric (not caesarian)

Perineal, vaginal genitalia

Radiology

Spine, back

Thyroid

Upper abdominal, diaphragm

$\begin{array}{rr}9 & 0.6 \\ 50 & 3.1\end{array}$

\begin{tabular}{lrr}
\hline & Mean & \multicolumn{1}{c}{ S.D. } \\
\hline Age of patient (in years) & 41.9 & 20.5 \\
Length of operations (in mins.) & 44.9 & 33.8 \\
$\begin{array}{lrr}\text { Recovery start score (RSS) } \\
\text { (score units) (all cases) }\end{array}$ & 8.3 & 4.3 \\
Rate of change of recovery score & & \\
$\quad$ (RATE) (score units/min.) & 0.9 & 0.6 \\
$\begin{array}{l}\text { Time to top score of 15 (COMP) } \\
\text { where applicable (mins.) }\end{array}$ & 13.4 & 9.5 \\
Recovery graph classification & & \\
$\quad$ TYPE 0 & 421 & 25.9 \\
TYPE 1 & 63 & 3.9 \\
TYPE 2 & 1142 & 70.2 \\
\hline
\end{tabular}


The data were then fed into a disc file on an ICL 1906s computer, and verified by a purpose-built program designed to detect errors, such as letters in the file where numbers were expected. Corrections were made manually with reference to the original study records.

The analysis was completed in several stages:

First the computer was programmed to plot each recovery graph and make calculations summarizing the graphs. The graphs of the recovery scores against time were summarized by three variables, which were not applicable in all the patients.

1. Recovery Start Score (RSS) - the first recovery score measured on entering the recovery room.

2. Rate - the gradient of the recovery scoretime graph. This measurement is based on a straight line fit of the recovery points and is only relevant when there are at least two points.

3. Complete recovery (COMP) - the time when the patient reached the top score of 15 .

These three variables, where applicable, were inserted on the computer file for further analysis.

The second stage of analysis was to investigate the range of normal for the recoveries and to classify the recovery graphs according to the type of anaesthetic, the patient's age, etc. The Statistical Package for the Social Sciences (SPSS)" was used for this analysis, allowing programming using pretested routines.

The final stage of analysis involved the use of a computer package called an Automatic Interaction Detector (AID). ${ }^{12}$ This program, which is frequently used in the analysis of survey data, allows the user to determine which of the many variables, such as age of patient, type of operation, best explains the variation seen in the variables describing recovery (for example RSS). The program works using the same method as a research worker manually sorting record cards into smaller sub-groups for analysis. A.I.D. gives results in terms of a "splitting tree" showing the power of each variable to effect the recovery; a summary of these results is given rather than printing out the complete splitting trees.

\section{RESULTS}

On printing out the recovery graphs for each patient, it was clear that they fell naturally into three groups:

Type 0. In 25.9 per cent of cases, there was only one point on the recovery graph, usually at a score of 14 or 15 .
Type I. In 3.9 per cent of cases. there were at least two points on the recovery graph but they were not at the specified spacing of five minutes. In one case the interval was 43 minutes. In many of these cases, the graph showed a spurious plateau at the top score of 15 .

Type 2. In 70.2 per cent of cases, there were at least two points at the specified five minute intervals. In all cases there was an upward trend in the graph and no plateaus. The summary variables RATE and COMP were calculated for this group alone.

Table II shows the analysis of all patients. A large number of females and minor operations is evident, laparoscopy being classified as a minor operation. Most patients received halothane, and over half did not receive any narcotic analgesics. Lower abdominal, dental, nose and throat and gynaecological procedures made up the majority of operations, with an overall mean length of operation of 44.9 minutes, and the high standard deviation (33.8 minutes) makes this figure compatible with a wide variety of types of surgery.

The recovery summary variables have been classified in Tables II \& III, and an overall recovery start score of 8.3 with a standard deviation of 4.3 score units suggests that patients enter the recovery room in all stages of recovery. The calculation of a linear correlation coefficient as part of the rate of change of recovery score (RATE) in the 1142 Type 2 recovery graphs, gave a minimum correlation coefficient of 0.83 . The mean rate of change of recovery score (RATE) (Table III) in the Type 2 cases was found to be 0.9 units per minute (S.D. 0.6), a wide variation.

Figure $l$ is a three-dimensional histogram plotted from all the results. The view point has been adjusted to show the peaks (the number of cases) to the best advantage. The two peak values at time zero with scores of 5 and 15 suggest a bimodal distribution for the first score point on entry into the recovery room, and this may account for the large standard deviation in the result (Table II). Further weight is given to this by the markedly different first scores in patients with the Type 2 and Type 0 recovery graphs (Table III). The reduction in total numbers (the sum of all the histogram heights) with time, is the effect of patients reaching the top score (15) and being discharged to the wards. Table III shows the results of an analysis of all the patients subdivided by the type of recovery graph. The significance of the differences between the Type 0 and Type 2 recovery graphs is indicated, and it is clear that in most cases the Type 0 and Type 2 
TABLE III

Analysis of All Cases by Type of Recovery Graph

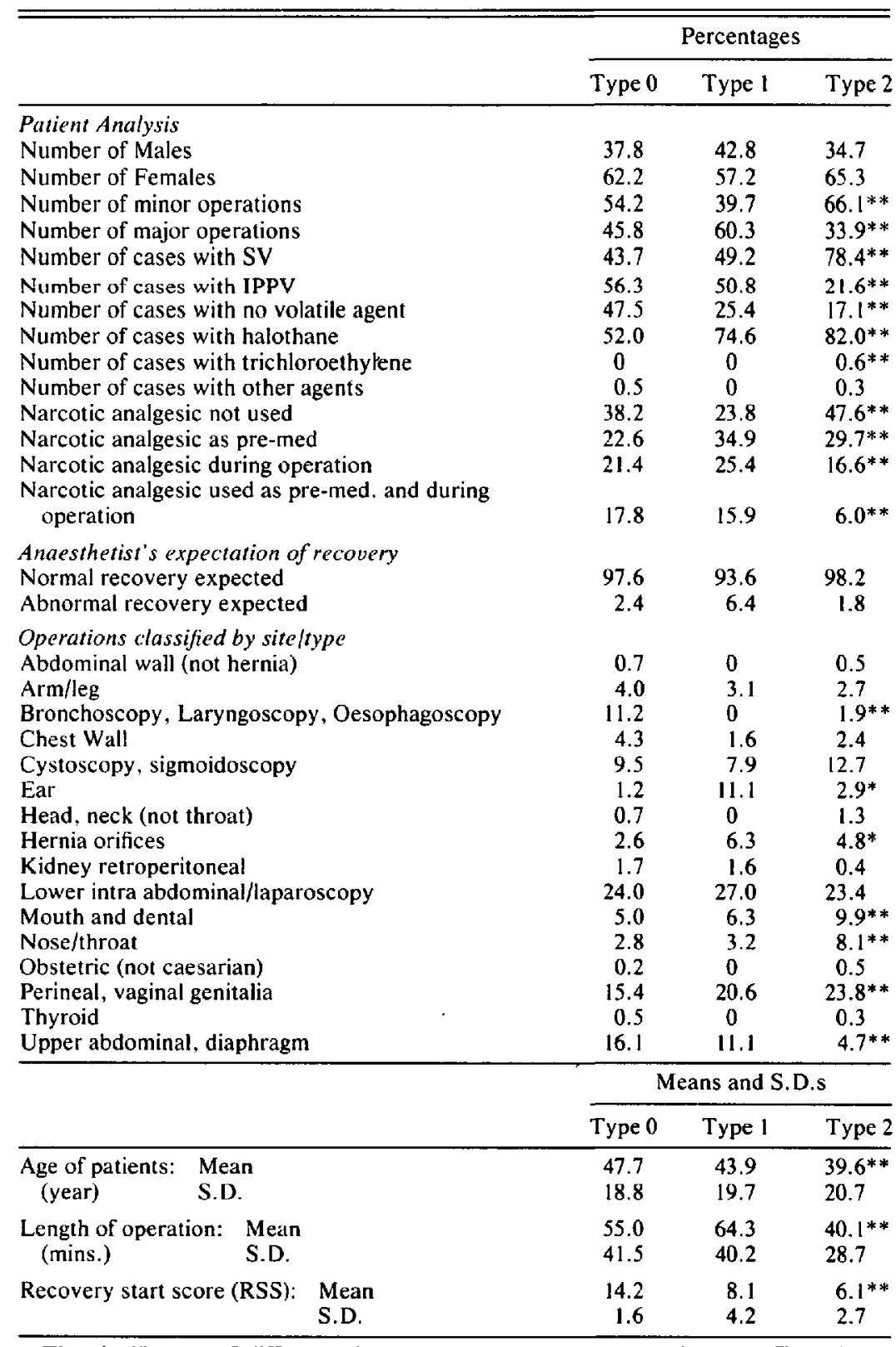

The significance of difference between percentages or means between Type 0 and Type 2 recovery is given by: ${ }^{*} \mathrm{P}<0.05 ;{ }^{* *} \mathrm{P}<0.01$.

recovery graphs seem to arise from two statistically distinct populations. The results for Type I graphs show features of both types ( 0 and 2$)$ and there is certainly a greater similarity between the Type 1 recovery graphs and either of the other two, than between Types 0 and 2 themselves.

The results of the analysis using the automatic interaction detector are shown in Table IV. The results give statistical answers to the question 'which group of variables (e.g. age, sex, type of operation) best explain the variation in the dependant variable, RATE, COMP, or RSS. It should be re-emphasized that RATE and COMP are interrelated, and are only calculated for the 1,142 patients showing Type 2 recovery graphs, but RSS applies to all patients. The results (Table 


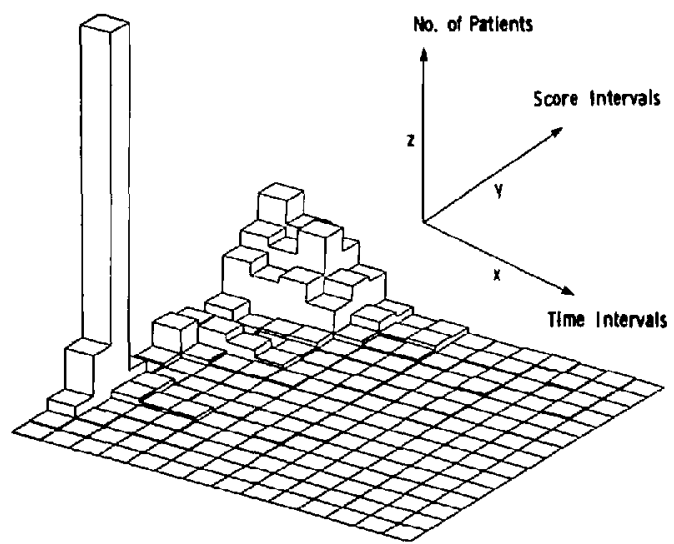

Figure 1 A three dimensional histogram showing the relationship between time in the recovery area ( 5 minute intervals), recovery score (one score unit intervals), and numbers of patients. A marked clustering is seen in the high score zone of the histogram, and an obvious bimodal distribution of patients on entry into the recovery room. The histogram refers to all the patients.

TABLE IV

Results of the ANalysis Using the AID Program

\begin{tabular}{lll}
\hline $\begin{array}{c}\text { Analysis of } \\
\text { Recovery Start } \\
\begin{array}{c}\text { Score } \\
\text { RSS }\end{array}\end{array}$ & $\begin{array}{c}\text { Analysis of Rate } \\
\text { of Change of } \\
\text { Recovery Score } \\
\text { RATE }\end{array}$ & $\begin{array}{c}\text { Analysis of } \\
\text { Time to } \\
\text { Topscore } \\
\text { COMP }\end{array}$ \\
\hline $\begin{array}{l}\text { SV or IPPV } \\
\text { Use of } \\
\text { Volatile }\end{array}$ & SV or IPPV & SV or IPPV \\
Agents & & \\
Age & Age & \\
Site of & Age \\
Operation & Opite of & \\
& $\begin{array}{l}\text { Operation } \\
\text { Major or }\end{array}$ & $\begin{array}{l}\text { Major or } \\
\text { Minor }\end{array}$ \\
& Operation & Operation \\
& & Sex of \\
& & Patient \\
\hline
\end{tabular}

The variables listed are those which best explain the variation in the recovery summary variables.

IV) show that the use of the predictor variables "ventilation (IPPV or SV)" and "age", play a large part in explaining the variation in all three dependent variables. The predictor variables, "the use of volatile agents" and "the site of operation" play a particular part in explaining the variation in RSS, and the variable "use of volatile agents" does not appear as a predictor variable for RATE or COMP. It is interesting that the anaesthetists's expectation of recovery did not have sufficient effect as a variable in the analysis to appear as a significant predictor in the results.

\section{Discussion}

This study raises four questions: (1) How easy is it for the nurses to use the scoring system and how repeatable is it? (2) What are the limitations of its use? (3) What constitutes a normal recovery? (4) What factors over which the anaesthetists has some control directly effect the recovery of his patient?

(1) Using the system. When the idea of using a scoring system was introduced to the recovery nurses, they were dubious about how long it would take to apply. During the pilot study the recovery nurses practised using the scoring system with the author's help, and they found that the mean time to make an assessment was 27 seconds. Once the staff were using the system regularly they commented that much of the stress of recovery care had disappeared as they knew exactly what to expect.

At the end of the pilot study a test of repeatability was undertaken. Pairs of nurses were asked to measure the recovery score independently and report their results. The paired measurements in each case were completed within one minute. Out of 27 paired measurements, there was only a divergence of one score point. When the whole study was completed the recovery staff had already incorporated the system into their student nurse training schedule.

(2) Limitations. The normal ranges determined in this study are strictly only applicable to the environment of the study. The range of surgery and anaesthesia was fairly conventional except that there was a rapid turnover of minor gynaecological cases (Table II). Most of the patients received a classical thiopentone, nitrous oxide, oxygen, halothane anaesthetic. In view of these circumstances, this range of cases may be found fairly widely and, therefore, the normal ranges may provide a useful guideline elsewhere. If there is a wide divergence in the types and proportions of surgery elsewhere, then a local study of the normal ranges would be advisable.

A further limitation that came to light during the study was that some patients showed abnormal progress in their scores because of deafness, this occurring in aged patients or after ear operations.

Pain during the immediate recovery period may cause limitation in ventilation, especially after upper abdominal operations (Tables II and III). In these cases, adequate analgesia was necessary and 15 per cent of all patients received analgesics before leaving the recovery room. The 
time course of drugs given intramuscularly during the immediate recovery phase is probably such that they would have little effect on the progress of recovery. This aspect of recovery care is the subject of a further study.

(3) What is a normal recovery? On entry into the recovery room there is a wide range of recovery scores (Figure 1 and Table II), and it seems that the distribution is bimodal. This is further emphasized by the significant differences in RSS associated with the three types of recovery graph (Table III). In one sense, classification of recovery graphs by the number of points and their time intervals is arbitrary, when one considers that the Type 0 graphs are probably a special case of Type 2. It is possible, however, that different anaesthetic techniques give rise to different recovery graphs, and the results in Table III give some support to this in that most of the minor operations anaesthetized with halothane and spontaneous ventilation appear with a Type 2 graph. Patients receiving intermittent positive pressure ventilation (IPPV) with no volatile agent for major operations, as in the upper abdomen, tend to have a Type 0 recovery graph, starting with a high score (mean $14.2 \pm 1.6$ score units).

It seems that a normal first point on the recovery graph (RSS) is difficult to define, as it depends on the type of anaesthetic. If the patient was ventilated he will probably have one high point on the recovery graph (Type 0 ). Plainly, the first point (RSS) determines the type of progress; if the first point is at 14 , there is little recovery left to be done.

The normal for the rate of change of recovery score is more difficult to define; this is only applicable to the recovery graphs Type 1 and 2 as one point is insufficient to define a trend. The problem lies in the interpretation of the Type 1 graph, where the measurements are not at the specified five-minute intervals, and where some of the graphs have plateaus. A plateau in a recovery graph probably indicates some abnormality in the recovery; but as plateaus were not found on the Type 2 recoveries, their reliability cannot be determined. For these reasons, the author considers that, though there are interesting abnormalities (e.g. plateaus) in the 63 Type 1 graphs, the fact that the measurement protocol was not followed exactly means that the data must be disregarded and the range of normal for RATE and COMP computed from the 1,142 Type 2 graphs alone. Table III shows the ranges for these variables. A patient who enters the recovery area with a score of 6 units could be expected to recover at the rate of 0.9 (S.D. 0.6) score units per minute and to reach a top score of 15 units 13.4 (S.D. 9.5) minutes after entry.

The situation can be summarized by saying that if the patient enters the recovery area with a score of 14 or 15 , he is safe anyway; but if he enters with a score in the region of 4-6, then he should be fully awake and safe in 13.4 (S.D. 9.5) minutes. This observation has important implications for planning recovery facilities, giving some index of patient turnover. It should be emphasized, however, that this type of prediction (COMP) is only valid when the scoring system is being used carefully at five minute intervals.

(4) How the anaesthetist can control recovery. The analysis of the data using the AID program (Table IV) shows that the anaesthetist's decision to use spontaneous or assisted ventilation has the greatest overall effect on dependent variables (RSS, RATE, COMP), the age of the patient being outside the anaesthetist's control.

The results of analysis for RSS (Table IV) are very much as would be expected from clinical experience. For example, the RSS is obviously higher if the young patient is anaesthetized without a volatile agent for cystoscopy, and his ventilation is controlled.

The use of RATE as a dependent variable produces a slightly different selection of predictor variables (Table IV) and, in fact, they can all be summarized by the concept of minor operation, the sites of operation specified in the full results being those where minor or day case surgery is done, for example $D \& C$, cystoscopy, toe-nail avulsion.

The analysis of COMP combines features of RSS and RATE.

It is interesting to note that the variables "length of the operation", "the anaesthetist's expectation of recovery" and "the use of analgesics" do not make an important contribution to the recovery within the limits of this study.

\section{Conclusions}

A simple and practical method of measuring the progress of immediate recovery from anaesthesia is presented and normal ranges are defined. The system gives the nurse clearer indication of recovery progress than the traditional observations of pulse and blood pressure.

It is important that the results of the scoring system conform to clinical impressions, for example in the rate of recovery of ventilated patients, as the scoring system must then be truth- 
fully quantifying the signs that the anaesthetist observes. If the results did not conform to experience, then one would suspect that vital information was being missed.

\section{ACKNOWLEDGEMENTS}

The author gratefully acknowledges the help and advice of the anaesthetists in Stoke City General Hospital and particularly the recovery staff who collected so much information with accuracy and patience.

Thanks are also due to Mrs. Davis for typing the manuscript.

\section{REFERENCES}

1. Bodlander, F.M.S. Deaths associated with anaesthesia. Brit. J. Anaesth. 47: 36 (1975).

2. Edwards, G., Morton, H.J.V., Pask, E.A. \& WYLIE, W.D. Deaths associated with anaesthesia. Andesthesia 1/: 194 (1956).

3. Clifton, B.S. \& Hotten, W.I.T. Deaths associated with anaesthesia. Brit. J. Anaesth. 35:250 (1963).

4. STEWARD, D.J. A simplified scoring system for the post-operative recovery room. Can. Anaesth. Soc. J. 22: 111 (1975).

5. Aldrete, J.A. \& Kroulik, D. A post anaesthesia recovery score. Anes. Analg. Current Researches 49: 924 (1970).

6. Carignan, G., Keéri-Szàntò, M. \& Lavellée, $\mathrm{J}$. Post anaesthetic scoring system. Anesthesiology 25: 396 (1964).

7. Robertson, G.S., MacGregor, D.M. \& Jones, C.J. Evaluation of doxapram for arousal from general anaesthesia in out-patients. Brit. J. Anaesth. 49: 135 (1977).

8. Kallos, T. Open mouthed head lifting, a sign of incomplete reversal of neuromuscular blockade. Anesthesiology 37: 650 (1972).

9. Grogono, A.W. \& Deacock, A.R. DE C. Assessing the safety of comatose and post anaesthetic patients. Brit. Med. J. 2: 174 (1974)

10. Tunstall, M.E. \& Beveridge, M.E. Assessing the Safety of comatose and post anaesthetic patients. Brit. Med. J. 2: 669 (1974).

11. Nie, N.H., Huld, C.H., Jenkins, J.G., SteinBRENNER, K., \& BENT, D.H. Statistical package for the social sciences, 2nd ed., McGraw-Hill Book Co., U.S.A. (1975).

12. Sonquist, J.A. \& Morgan, J.N. The detection of interaction effects, the report on a computer program for the selection of optimal combinations of explanatory variables. Monograph No. 35. The Institute for Social Research (Survey Research Centre), Michigan, U.S.A. (1964).

\section{RÉSUMÉ}

On décrit ici un système de pointage permettant la mesure de l'émergence de l'anesthésie en salle de réveil et l'on présente une évaluation de la méthode. Un score est établi à partir de l'évaluation des fonctions cognitive, motrice, respiratoire et hémodynamique.

On a étudié ce système chez 1626 opérés. Les évaluations étaient faites à l'arrivée des patients en salle de réveil et rẻpétées aux cinq minutes jusqu'à atteinte du score maximal (15). On inscrivait les résultats en fonction du temps sur des graphiques individuels.

L'analyse des résultats indique que les patients ventilés mécaniquement avaient tendance à arriver à la salle de réveil avec un score de 14 ou 15 (score maximal), alors que les autres arrivaient en général avec des scores inférieurs et progressaient vers la récupération complète au rythme de $0.9 \pm 0.6$ point par minute. L'analyse multifactorielle des résultats a confirmé que la décision de l'anesthésiste d'utiliser la respiration contrôlée ou la respiration spontanée étaient le facteur individuel le plus important pour prédire la vitesse de remontée du score d'éveil.

Il est suggéré que ce système, qui présente une bonne corrélation avec la clinique, est un outil utile pour l'infirmière de la salle de réveil. 